\title{
Correction to: In situ assessment of soil dynamic parameters for characterizing nonlinear seismic site response using KiK-net vertical array data
}

\author{
Hai-Yun Wang ${ }^{1}(\mathbb{D}) \cdot$ Wei-Ping Jiang ${ }^{1}(\mathbb{D}) \cdot$ Su-Yang Wang ${ }^{1,2}(\mathbb{D}) \cdot$ Yu Miao $^{2}(\mathbb{D}$
}

Published online: 2 January 2019

(c) Springer Nature B.V. 2019

\section{Correction to: Bulletin of Earthquake Engineering https://doi.org/10.1007/s10518-018-00539-3}

We are very sorry to report a mistake in our recent paper (doi.org/10.1007/s10518-01800539-3), which left one of the authors (Kenneth W. Campbell) in a reference (Kim B, Hashash YM, Stewart JP, Rathje EM, Harmon JA, Musgrove MI, Silva WJ (2016) Relative differences between nonlinear and equivalent-linear 1-D site response analyses. Earthq Spectra 32(3):1845-1865).

The correct reference format is listed as follows:

Kim B, Hashash YM, Stewart JP, Rathje EM, Harmon JA, Musgrove MI, Campbell KW, Silva WJ (2016) Relative differences between nonlinear and equivalent-linear 1-D site response analyses. Earthq Spectra 32(3):1845-1865.

Publisher's Note Springer Nature remains neutral with regard to jurisdictional claims in published maps and institutional affiliations.

The original article can be found online at https://doi.org/10.1007/s10518-018-00539-3.

Su-Yang Wang

suyangwang@whu.edu.cn

1 Institute of Engineering Mechanics, China Earthquake Administration, Xuefu Road 29, Harbin 150080, People's Republic of China

2 School of Civil Engineering and Mechanics, Huazhong University of Science and Technology, Luoyu Road 1037, Wuhan 430074, People's Republic of China 